\title{
Vital rates of two small populations of brown bears in Canada and range-wide relationship between population size and trend
}

\author{
Michelle L. McLellan ${ }^{1}$ (D) | Bruce N. McLellan ${ }^{2}$ | Rahel Sollmann ${ }^{3}$ | Heiko U. Wittmer ${ }^{1}$
}

${ }^{1}$ School of Biological Sciences, Victoria University of Wellington, Wellington, New Zealand

${ }^{2}$ Southwest British Columbia Grizzly Bear Project, D'Arcy, BC, Canada

${ }^{3}$ Department of Wildlife, Fish, and Conservation Biology, University of

California Davis, Davis, CA, USA

\section{Correspondence}

Michelle L. McLellan, School of Biological Sciences, Victoria University of Wellington, PO Box 600, Wellington 6140, New Zealand. Email: mclellan.wildlife.research@gmail.com

Funding information

British Columbia Ministry of Forests, Lands, and Natural Resource Operations; British Columbia Ministry of Environment; Habitat Conservation Trust Foundation, Grant/ Award Number: 3-283; Victoria University of Wellington

\begin{abstract}
Identifying mechanisms of population change is fundamental for conserving small and declining populations and determining effective management strategies. Few studies, however, have measured the demographic components of population change for small populations of mammals ( $<50$ individuals). We estimated vital rates and trends in two adjacent but genetically distinct, threatened brown bear (Ursus arctos) populations in British Columbia, Canada, following the cessation of hunting. One population had approximately 45 resident bears but had some genetic and geographic connectivity to neighboring populations, while the other population had $<25$ individuals and was isolated. We estimated population-specific vital rates by monitoring survival and reproduction of telemetered female bears and their dependent offspring from 2005 to 2018. In the larger, connected population, independent female survival was 1.00 (95\% Cl: 0.96-1.00) and the survival of cubs in their first year was 0.85 (95\% Cl: 0.62-0.95). In the smaller, isolated population, independent female survival was 0.81 (95\% Cl: 0.64-0.93) and first-year cub survival was $0.33(95 \% \mathrm{Cl}$ : $0.11-0.67)$. Reproductive rates did not differ between populations. The large differences in age-specific survival estimates resulted in a projected population increase in the larger population $(\lambda=1.09 ; 95 \% \mathrm{Cl}: 1.04-1.13)$ and population decrease in the smaller population ( $\lambda=0.84 ; 95 \% \mathrm{Cl}: 0.72-0.95)$. Low female survival in the smaller population was the result of both continued human-caused mortality and an unusually high rate of natural mortality. Low cub survival may have been due to inbreeding and the loss of genetic diversity common in small populations, or to limited resources. In a systematic literature review, we compared our population trend estimates with those reported for other small populations ( $<300$ individuals) of brown bears. Results suggest that once brown bear populations become small and isolated, populations rarely increase and, even with intensive management, recovery remains challenging.
\end{abstract}

\section{KEYWORDS}

brown bear, carnivore conservation, grizzly bear, population recovery, small population, survival, Ursus arctos

This is an open access article under the terms of the Creative Commons Attribution License, which permits use, distribution and reproduction in any medium, provided the original work is properly cited.

(c) 2021 The Authors. Ecology and Evolution published by John Wiley \& Sons Ltd. 


\section{1 | INTRODUCTION}

Many of the world's terrestrial large carnivore populations are declining (Ripple et al., 2014). In most cases, the principal causes of decline are habitat loss, habitat fragmentation, as well as humancaused mortality from legal harvest, conflict with humans for safety or livestock, and persecution. Independently or synergistically, these factors erode the geographic ranges of species, contracting and fragmenting populations, leaving increased interface edges and population isolates (Henschel et al., 2014; Kenney et al., 2014; Proctor et al., 2012; van Oort et al., 2011). At some point along the continuum of decline, the initial causes may become outweighed in their effect by additional threats arising as a function of diminishing population size. Threats associated with small population sizes include an increased vulnerability to demographic stochasticity, loss of genetic variability, and Allee effects (Berec et al., 2007; Brook et al., 2008; Caughley, 1994).

Successful conservation requires an understanding of the initial causes of decline and those that might be specific to small, remnant populations (Brook et al., 2008; van de Kerk et al., 2019). Many threatened large carnivore species are wide-ranging, occur at lowdensity, and have long generation times. Therefore, even in large populations, it unavoidably takes years to collect sufficient sample sizes of vital rates to infer population trends and their underlying mechanisms (e.g., Gough \& Kerley, 2006; Regehr et al., 2018; Schwartz et al., 2006). For small populations, with inevitably small sample sizes, acquiring data required for strong inferences is improbable (Mosnier et al., 2015; Zipkin \& Saunders, 2018). As a result estimates of vital rates and causes for their suppression are seldom obtained in wild populations with few individuals (e.g., Tosoni et al., 2017; Wittmer et al., 2005), despite their world-wide relevance for the development of effective conservation strategies.

Brown bears (Ursus arctos; Figure 1), called grizzly bears over most of North America, are large-bodied, long-lived omnivores with late onset of reproduction. Females are predominantly philopatric and therefore do not rapidly colonize neighboring habitats or provide demographic rescue to small populations, while males will often

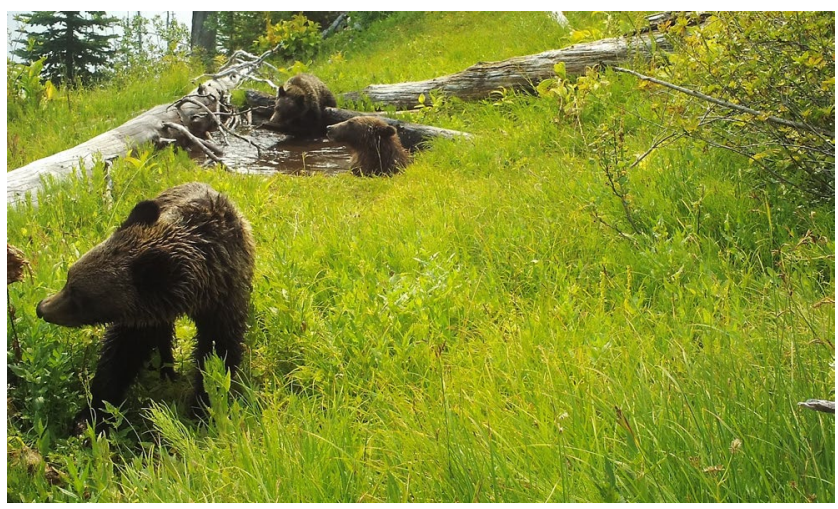

FIGURE 1 Mother brown bear and offspring in a waterhole. These bears are part of the growing McGillvary Mountains population in southwest British Columbia, Canada disperse outside of their natal home range (McLellan \& Hovey, 2001; Proctor et al. 2004). Brown bears usually reach maturity between 4 and 6 years of age, and females remain with dependent offspring for two or more years (Garshelis et al., 2005; Mace et al., 2012; McLellan, 2015; Schwartz et al., 2006). Brown bears typically have high (>95\%) annual adult survival probabilities even as populations approach carrying capacity, and population regulation occurs due to variable recruitment rates that reflect the abundance of food or other density-dependent effects (Keay et al., 2018; McLellan, 2015; Schwartz et al., 2003; van Manen et al., 2015). As a result, recovery efforts for this species usually target adult female survival, which is often reduced by human-caused mortality.

Substantial range contraction has resulted in a fragmented global population of brown bears with many small isolates in need of conservation attention (Mattson \& Merrill, 2002; McLellan et al., 2017; Zedrosser et al., 2001). There have been several successful efforts to recover such brown bear populations. For example, in the 1930s, as few as 130 brown bears remained in Sweden but following a reduction in human-caused mortality, the population grew to approximately 700 by the mid-1990s (Swenson et al., 1995), and to over 3,200 bears by 2008 (Kindberg et al., 2011). In the United States, brown bear populations in both the Yellowstone Ecosystem and in northern Montana grew at up to $7.6 \%$ annually for over 20 years (Mace et al., 2012; van Manen et al., 2015) to over 700 bears in each population (Haroldson et al., 2014; Kendall et al., 2009) following the reduction of human-caused mortality.

Not all recovery attempts of brown bear populations, however, have resulted in marked population increases. In Italy, the relict Apennine bear population has been isolated from other brown bears for more than 1,000 years (Benazzo et al., 2017) and in recent times, consistently numbered between 50 and 60 individuals without evidence of increase notwithstanding persistent conservation efforts (Gervasi et al., 2017). In the French Pyrenees, brown bear populations declined to $<10$ individuals in 1990 , and, despite efforts to reduce adult mortality, by 1995 only five individuals remained in the western part of the range and the central population required reintroduction with bears from Slovenia (Chapron et al., 2003). Reasons for variable outcomes of recovery efforts in brown bears remain poorly understood but may be related to the small size and increasing isolation of remnant populations.

Here, we use data collected from telemetered brown bears to estimate causes of mortality, age-specific survival probabilities, reproductive rates (age of primiparity, litter size, and interbirth interval), and population growth in two adjacent but genetically separate populations at the southern edge of brown bear distribution along the Coast Mountains of British Columbia, Canada. Previous research using genetic-based mark-recapture monitoring of these populations from 2005 to 2017 identified divergent population trends following the cessation of legal hunting (i.e., human-caused mortality) in 2000 (McLellan et al., 2019). Specifically, the larger, higher density McGillvary Mountains population, with some genetic and demographic connectivity to other large populations, was estimated to increase at $2 \%$ each year while the adjacent, small $(<25$ bears) and 
long-isolated (Apps et al., 2014; McLellan et al., 2019) North SteinNahatlatch population declined by approximately $5 \%$ each year. We then compare our population growth estimates to those published for other small ( $<300$ individuals) brown bear populations across their distribution using a literature review. Combined, our two objectives aim to better understand the relationship between population size, connectivity, and vital rates in brown bears, contributing not only to our understanding of the effectiveness of brown bear recovery efforts but also to the limited empirical knowledge on small population demography in general.

\section{2 | METHODS AND MATERIALS}

\section{1 | Study area}

The McGillvary Mountains and North Stein-Nahatlatch populations are located in the Coast Mountains of British Columbia, Canada (Figure 2). The McGillvary Mountains population has approximately 45 resident bears, and one-quarter of its geographic perimeter was connected to other bear populations to the north, while the North Stein-Nahatlatch population has fewer than 25 individuals and appeared genetically isolated (Apps et al., 2014; McLellan et al., 2019). The western portion of the study area is a temperate rain forest dominated by western red cedar (Thuja plicata) and western hemlock (Tsuga heterophylla). At high elevations, the winter snowpack is deep and a maritime climate results in moderate summer temperatures. The eastern portion of the study area is warmer and dryer; Douglas-fir (Pseudotsuga menziesii) dominates low elevation forests, and higher elevation forests consist mostly of Engelmann spruce (Picea engelmannii) and subalpine fir (Abies lasiocarpa) ranging eastward from wet variants of the forest to very dry variants (MacKenzie, 2012). Alpine ecosystems range from lush, moist herbaceous meadows to dry heather (Cassiope spp.) and rock dominated topography. The average annual rainfall is approximately $1,030 \mathrm{~mm}$ on the western side and $400 \mathrm{~mm}$ on the eastern sides of the study area. Avalanche chutes are common throughout the study area and are often used by bears in the spring and early summer (McLellan \& McLellan, 2015). Mean road density is 0.21 and $0.16 \mathrm{~km} / \mathrm{km}^{2}$ in the McGillvary Mountains and North Stein-Nahatlatch populations, respectively, and each has similar amounts of settled lands along their perimeters.

\section{2 | Bear capture and monitoring}

We captured, collared, and monitored bears from 2005 to 2018. Bears were immobilized by darting from a helicopter (see McLellan \& McLellan, 2015). Capture was carried out in spring, shortly after den emergence when bears were feeding in avalanche chutes and open alpine meadows, or early autumn when they fed on huckleberries (Vaccinium membranaceum). Once immobilized, we weighed, measured, and fitted bears over 2 years old with either GPS or VHF collars (Lotek Inc.). We also obtained a tissue sample for genetic identification and a vestigial premolar for determining age via cementum annuli. We classified 2 to 5 -year-old female bears as subadults and those 6 years and older as adults (Garshelis et al., 2005). Insufficient data were collected from males to include in this analysis. All collars had canvas spacers to ensure that the collar would drop off, and we weakened the canvas on the collars of subadult bears to ensure they dropped in about 1 year. The Animal Care Committee of the British Columbia Fish and Wildlife
FIGURE 2 Extant (green) and vagrant (yellow) brown bear distribution in North America (inset) and southwest British Columbia, Canada. The geographic boundary between the genetically distinct McGillvary Mountains (MM) and North Stein-Nahatlatch (NSN) brown bear populations bisects the study area (blue dash) centered at 50.579181, -122.400917 . Highways (red lines), major rivers (blue lines), international border (bottom solid black line)

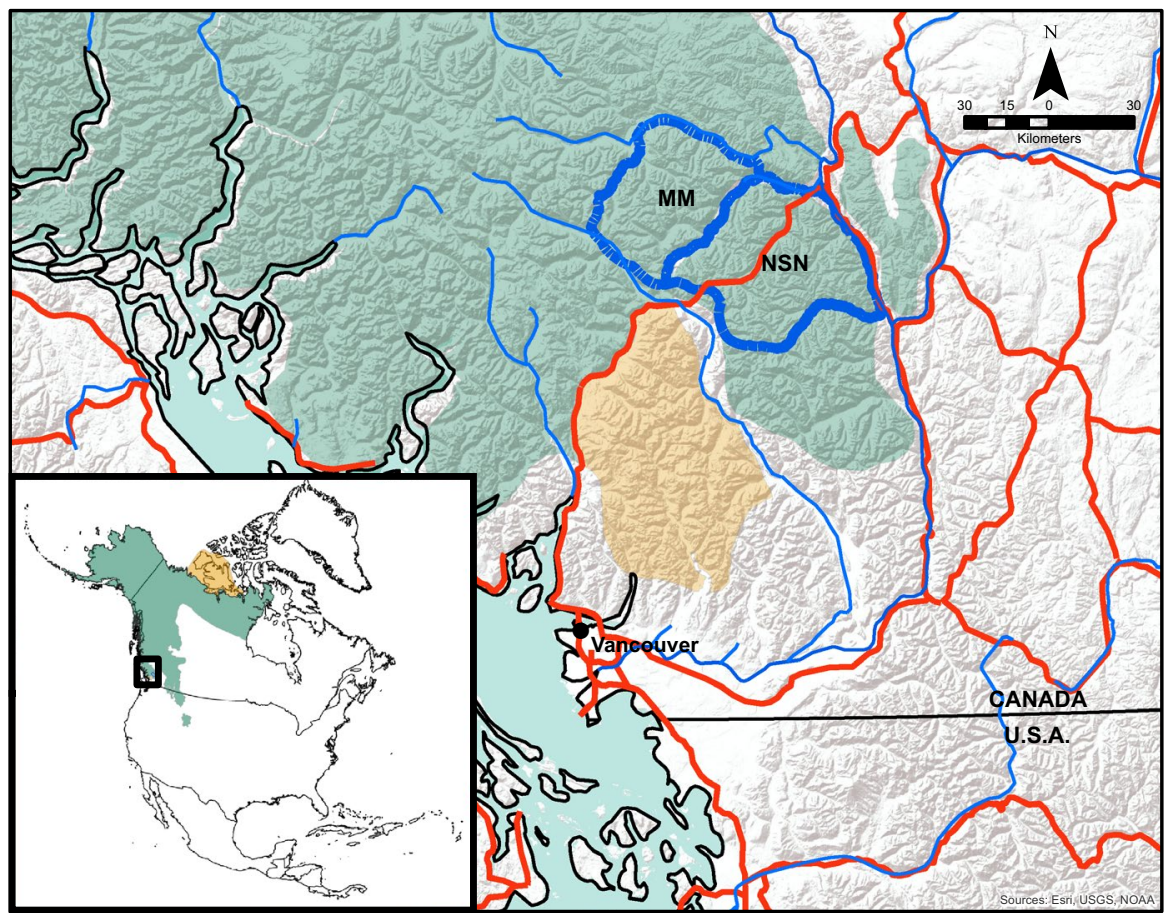


Management Branch approved and permitted all capture and handling protocols.

Capture effort, defined as the time we spent searching for bears, was evenly distributed between the study populations until 2014 when it had become apparent that the North SteinNahatlatch population was not only small, but had an unusually high incidence of adult female mortality. Although no bears had been injured or killed in our research, the risk of additional female mortality due to capture was deemed too high, so captures from 2015-2018 were limited to the McGillvary Mountains population. We continued to monitor the vital rates of all collared bears in both populations until 2018 .

Throughout the first part of the study (2005-2008), we located collared bears by fixed-wing aircraft every 2 weeks from May to November. On each flight, we downloaded GPS location data and attempted to visually locate each bear and count the dependent offspring of females. If we did not find a bear for more than 8 consecutive weeks, we censored them from the analyses estimating survival and reproductive parameters at the time of their last known status. The populations were also monitored using genetic capture-recapture, and all females were genetically detected after their collars had dropped or stopped working; therefore, all had known fates while collared. In the second part of the study (20102018), some females were fit with VHF collars to reduce the number of recaptures needed to maintain continuity of monitoring. Collared bears were subsequently located and observed from a helicopter at least once each spring and then again in summer and fall. We intermittently located bears from the ground between aerial attempts. Offspring age was determined by size for cubs (bears $<1$-year-old) and yearlings. We grouped attendant offspring that were 2 years of age and older because we could not visually distinguish between 2 and 3-year-old bears with certainty if the previous year's status was unknown.

All collars were programmed to signal if the collar had not moved in $24 \mathrm{hr}$, and these mortality signals were investigated as soon as possible after detection. Whenever we found a dropped collar with rotted canvas, we assumed the bear was still alive. If a bear was found dead, we performed an investigation and necropsy in the field to determine the cause of death.

\section{3 | Survival analysis}

We estimated survival (S) for adult and subadult female bears using the staggered entry design for the Kaplan-Meier estimator (Pollock et al., 1989). We considered population (S Pop) and age class (S Age) as categorical covariates in candidate models along with the null model (S 1) because we were interested in establishing whether the previously identified differences in population trend (McLellan et al., 2019) were indicative of differences in population-specific survival and because survival often differs among age classes (Mace et al., 2012; McLellan, 2015; Schwartz et al., 2006). We used months as our monitoring interval from April to October when most bears were active (McLellan \& McLellan, 2015) and amalgamated November through March into one monitoring interval because monthly mortality would not be distinguishable when bears were hibernating. We used RMark v.2.25 (Laake \& Rexstad, 2008; White, 2008) to fit models and compared models using AIC. Models that deviated from the top model with $<2 \triangle \mathrm{AIC}$ units were averaged to obtain survival estimates for each population and age class (Burnham \& Anderson, 2004). For consistency with analysis of reproductive parameters (below), we also tested for statistical significance of effects present.

We estimated cub survival by observing the number of cubs for each collared female shortly after den emergence and at least once before the following denning season. We assumed cub mortality if they were no longer seen with their mothers. We censored from analysis bears with cubs not located within a month of den emergence or mothers that dropped their collars or that were not visually located again that year. Due to a possible lack of independence of cub survival within a litter (Mace et al., 2012; Swenson et al., 2001), we first tested whether individual cub survival differed from survival within litters using an ANOVA and then tested for a difference in cub survival between populations. We resampled with replacement (bootstrapped) cub survival data 1,000 times to obtain mean survival and 95\% confidence intervals (McLellan, 2015). We used the same method to estimate yearling survival. Analyses were conducted using PopTools (Hood, 2011).

\subsection{Age of primiparity, litter size, and interbirth interval}

We located all telemetered females shortly after den emergence in spring to determine whether they had reproduced and to count the number of offspring.

To estimate the average age of primiparity, we used the techniques developed by Garshelis et al. (1998). This method incorporates data from all monitored nulliparous females, including those not monitored to parturition. For each age, the proportion of females in the sample that reproduced are weighted by the proportion of females in the study population available to have a first litter at each age. The resulting estimates are not biased toward early maturing bears, which, due to shed collars and mortality, are less likely to be lost from the sample than late-maturing bears. We used the same weighting technique of Garshelis et al. (1998) as adapted by McLellan (2015) to estimate the average interbirth interval for each population. We used data from all collared females for which one or more birthing events were known. The proportion of the female sample that had a subsequent litter during each year following the birth year was used to estimate breeding intervals without bias toward shorter intervals. For each parameter, the means and confidence intervals were obtained for each population by bootstrapping the original sample 1,000 times using PopTools (Hood, 2011). 


\section{5 | Reproductive state transition and reproductive rate}

The stable reproductive state distribution describes the proportion of adult females in each reproductive state (Schwartz \& White, 2008). For brown bears, female reproductive state is defined by the presence and age of dependent offspring: alone (A), with cubs $(C)$, with yearlings $(Y)$, or with 2-year-old or older offspring $(T)$. To obtain an estimate of each population's stable reproductive state distribution, we first estimated the probability that a female will transition from one reproductive state to another using the multistate model in RMark (Laake \& Rexstad, 2008). We considered ten biologically possible transitions that are observable when an adult female is monitored for two or more consecutive years. Because survival and recapture are a prerequisite for observing a transition, their probabilities are set to 1.0. The resulting estimates are used to populate a transition matrix (right in Equation 1) that, when multiplied by a hypothetical starting state matrix (left in Equation 1; in this case all females are alone), gives the reproductive state distribution after one transition ( $t 2$; Equation 1).

$$
t 2=\left[\begin{array}{llll}
1 & 0 & 0 & 0
\end{array}\right]\left[\begin{array}{cccc}
A A A C & 0 & 0 \\
\text { CA CC CY } & 0 \\
\text { YA YC } & 0 & Y T \\
\text { TA TC } & 0 & 0
\end{array}\right]
$$

We then iteratively multiplied the resulting age distribution by the transition probability matrix in a Markov chain until it reached the asymptotic stable reproductive state distribution. For this analysis, we used markovchain package v. 0.6.9.15 (Spedicato et al., 2014) in program R (v.3.6.1; R Core Team, 2019). We resampled the data with replacement and bootstrapped estimates of the stable reproductive state distribution 1,000 times to estimate means and $95 \%$ $\mathrm{Cls}$ for each population. We did not have a sufficient sample size to include female age as a covariate for transition probabilities.

We estimated the mean reproductive rate ( $m_{x ;}$ female cubs/year/ female) for each population by multiplying the estimated number of female cubs per litter by the stable reproductive state proportion of females with cubs (Schwartz \& White, 2008). Because the sex of each cub was not determined, we assumed the number of female cubs to be half the total number of cubs. Like all methods that pool data across time, this method for estimating the reproductive rate assumes constant transition probabilities, but is more robust to possible sampling bias from capture and variability in monitoring duration than by simply using the proportion of monitored individuals (Schwartz \& White, 2008).

\subsection{Population growth and stable age distribution}

We estimated finite population growth rate $(\lambda)$ by constructing an age-structured matrix population (Leslie matrix) model using repeated random samplings (Monte Carlo estimation) from the bootstrapped probability distributions of age-specific survival and reproduction for each population (Mace et al., 2012). We considered the age of last reproduction as 24 years (McLellan, 2015; Schwartz et al., 2003). For each iteration, we solved for the dominant eigenvalue, which is the population growth rate. For each population, we also estimated the net reproductive rate $\left(R_{0}\right)$, defined as the estimated number of female cubs an adult female will produce in her lifetime, and the mean generation time (GenT), defined as the time required for a typical female to produce $R_{0}$ offspring (Caswell, 2001). Analyses were conducted using the popbio v.2.2.4 package (Stubben \& Milligan, 2007) in program R (R Core Team, 2019). We repeated this process 1,000 times for each population to estimate the mean and variance for each latent variable.

We estimated the stable age distribution of each population by converting the age-structured matrix population model into a stagestructured population model. Because vital rates were estimated for age groups, only transition rates required calculation. The transition rate is the expected proportion of individuals transitioning from one life stage to the next and is conditional on individual survival and the population growth rate (Caswell, 2001; Fujiwara \& DiazLopez, 2017). We applied a conditional age group-transition rate described by Caswell (2001) where the probability that an individual will transition from one age group to the next $\left(P_{j, i}\right)$ is:

$$
P_{j, i}=\frac{\lambda^{-\left(x_{j}-x_{i}-1\right)} I\left(x_{j}-1\right)}{\sum_{x=x_{i}}^{x_{j}-1} \lambda^{-\left(x-x_{i}\right)} \mid(x)}
$$

and $\lambda$ is the population-specific growth rate, $x_{i}$ is the first age in stage $i, x_{j}$ is the first age in stage $j=I+1$, and $I(x)$ is the survivorship at time $x$. We repeated this process for all 1,000 bootstrapped Leslie matrices from the preceding analysis to estimate the confidence interval around each population's stable age class outcome (Mace et al., 2012).

\section{7 | Population growth estimates in small populations of brown bears}

To investigate the relationships between population size and population growth rates in small populations of brown bears, we used the IUCN Red List of Threatened Species, which lists all isolated populations globally (McLellan et al., 2017). We limited our search to unhunted populations that had fewer than 300 bears. Then, we used Google Scholar and Web of Science to search for additional information. Specifically, we searched the name of the country or region, the species, and the term "population" (e.g., "Himalaya" + "Ursus arctos" + "population") for each population we had identified above and only included populations for which there was a population size or trend estimate available. For populations with long histories of research and sometimes changing population size, we used the size estimated toward the beginning of population change and did not consider examples from populations that did not have temporally overlapping estimates of size and growth rate. We categorized the 
populations according to their known geographic or genetic connectivity (connected to other populations or isolated) and history of augmentation (augmented or not).

\section{3 | RESULTS}

Between 2005 and 2018, we captured and collared 25 independent female brown bears in the McGillvary Mountains $(n=16)$ and North Stein-Nahatlatch $(n=9)$ populations resulting in survival and reproductive data for 43.1 and 26.0 bear-years (cumulative number of years sampled for all bears) in each population, respectively.

\section{1 | Causes of mortality}

No collared females died in the McGillvary Mountains population while 5 collared, independent female bears died in the North SteinNahatlatch population resulting in 0.19 mortalities/bear-year of monitoring. Causes of mortality for females varied: Two nulliparous females (aged seven and eight, respectively) were illegally killed by humans. Three female bears died of natural causes amounting to 0.12 natural mortalities/bear-year; one adult (age 18) with an unknown reproductive state was killed in the early spring by another bear; one subadult (age 4) died in her den and was severely emaciated with severe gelatinous bone marrow transformation indicating starvation (Raglus et al., 2019); and one bear (age 20) died late in the fall with no sign of trauma and was suspected to have died due to natural senescence with a maxillary deforming dental abscess possibly a contributing factor.

\subsection{Survival of independent females}

Comparison of known-fate survival models indicated that survival differed between populations (Table 1), but not age class. Model averaged independent female survival was 1.00 (95\% Cl: 0.96-1.00) in the McGillvary Mountains and 0.81 (95\% Cl: 0.64-0.93) in the North Stein-Nahatlatch population (Table 2).

\subsection{Age of primiparity, interbirth interval, and litter size}

Six of the monitored females in the McGillvary Mountains were nulliparous during the course of the study; three did not reproduce by 6,7 , and 8 years old when they were censored because they had lost their collars, and one female reproduced for the first time at age 11. The remaining two had first surviving litters at age eight and nine. Although both these females were monitored from ages 3 to 7 and 6 to 8 , neither was observed the year immediately before having surviving cubs so could have had nonsurviving cubs at ages seven and eight, respectively. Two more females were first captured at age 7 with cubs.
TAB LE 1 Selection results of models estimating known-fate survival probabilities of collared female brown bears between 2005 and 2018 in southwest British Columbia, Canada

\begin{tabular}{lllll} 
Model & $n^{\mathrm{a}}$ & AICc & $\Delta$ AICc $^{\mathrm{b}}$ & $\omega^{\mathrm{c}}$ \\
\hline S ( Pop) & 2 & 51.52 & 0.00 & 0.978 \\
S $(\sim 1)$ & 1 & 59.71 & 8.19 & 0.016 \\
S ( Age) & 2 & 61.70 & 4.19 & 0.006 \\
\hline
\end{tabular}

Note: In addition to equal survival among groups $(\sim 1)$, models considered population ( Pop), either the McGillvary Mountains or North SteinNahatlatch population, and age class ( Age), subadults from 2 to 5 years and adults $\geq 6$ years, as factors contributing to survival.

${ }^{a}$ Number of model parameters.

${ }^{b}$ Difference between $\mathrm{AICc}$ of model and the $\mathrm{AICc}$ of the highest ranked model.

${ }^{\mathrm{c}}$ Model weight.

The estimated mean age of primiparity was 8.3 years $(95 \% \mathrm{Cl}: 7.0-$ 10.0) excluding possible nonsurviving first litters. Including the possible nonsurviving first litters, the mean age of primiparity would be 7.9 years (95\% Cl: 6.1-10.0). In the North Stein-Nahatlatch, the age of first surviving litter was observed for one bear at 12 years, and two nulliparous females died at ages 7 and 8 years old. We were unable to obtain estimates of primiparity with sufficient precision to compare populations.

Interbirth intervals did not measurably differ between populations. We observed six interbirth intervals and six partial intervals for eight females in the McGillvary Mountains, and four interbirth intervals for three females in the North Stein-Nahatlatch. The resulting estimates of interbirth interval were 4.08 years $(95 \%$ $\mathrm{Cl}: 3.63-4.67)$ and 4.50 years (95\% $\mathrm{Cl}: 4.00-5.00)$, respectively (Table 2).

Litter sizes were also similar in the McGillvary Mountains and North Stein-Nahatlatch. We estimated litter sizes based on 21 cubs in nine litters $(\bar{x}=2.33,95 \% \mathrm{Cl}: 1.89-2.78)$ in the McGillvary Mountains and nine cubs in four litters $(\bar{x}=2.25,95 \% \mathrm{Cl}: 2.00-2.75)$ in the North Stein-Nahatlatch (Table 2).

\subsection{Survival of dependent offspring}

We estimated the survival rates of cubs and yearlings as well as the reproductive rates of adult females from the reproductive events of 22 adult females (15 McGillvary Mountains, seven North Stein-Nahatlatch) that produced 20 cubs in eight litters in the McGillvary Mountains (the mother of the remaining litter lost her collar before the fall and thus did not contribute to offspring survival estimates) and nine cubs in four litters in the North Stein-Nahatlatch. Cub survival was 0.85 (95\% Cl: 0.62-0.95) in the McGillvary Mountains and 0.33 (95\% Cl: $0.11-0.67)$ in the North Stein-Nahatlatch. Cub survival was independent of litter membership ( $p=.97$ ); in the McGillvary Mountains, three cubs were lost from two litters ( 2 of 3 and 1 of 2 ) while all cubs in six other litters survived. In the North Stein-Nahatlatch, one litter of three was 
TABLE 2 Summary of survival rates by age class estimated using the KaplanMeier estimator from monitoring collared brown bears in the McGillvary Mountains (MM) and North Stein-Nahatlatch (NSN) populations from 2005 to 2018

\begin{tabular}{llll} 
& MM & NSN & $p$ value \\
\hline $\begin{array}{lll}\text { Survival } \\
\text { Cubs }\end{array}$ & $0.85(0.62-0.95)$ & $0.33(0.11-0.67)$ & .004 \\
$\quad$ Yearling & 1.00 & 1.00 & \\
$\quad$ Independent female & $1.00(0.96-1.00)$ & $0.81(0.64-0.93)$ & .002 \\
\hline $\begin{array}{l}\text { Reproduction } \\
\text { Litter size }\end{array}$ & $2.33(1.89-2.78)$ & $2.25(2.00-2.75)$ & .837 \\
$\quad \begin{array}{l}\text { Proportion females with } \\
\text { cubs }\end{array}$ & $0.20(0.13-0.30)$ & $0.17(0.07-0.26)$ & .625 \\
$\quad$ Interbirth interval (years) & $4.08(3.63-4.4 .67)$ & $4.50(4.00-5.00)$ & 0.780 \\
m 6 -24 & $0.23(0.16-0.38)$ & $0.19(0.09-0.31)$ & \\
\hline
\end{tabular}

Note: Bootstrapped survival estimates for cubs (first year of life), yearlings (age $=1$ ). Independent females included both subadults ( $2-5$ years) and adults (6-24 years). Reproductive rates for adult females ages 6-24 years $\left(m_{6-24}\right)$ estimated based on monitoring collared females with cubs. There were no yearling mortalities and therefore no variance estimates.

\begin{tabular}{|c|c|c|c|c|c|}
\hline \multirow[b]{2}{*}{ Population } & \multirow{2}{*}{$\begin{array}{l}\text { From } \\
\text { state }\end{array}$} & \multicolumn{4}{|l|}{ Transfer to state } \\
\hline & & Alone & Cubs & Yearling & Twos \\
\hline \multirow[t]{4}{*}{ MM } & Alone & $0.63(0.38-0.82)$ & $0.38(0.18-0.62)$ & & \\
\hline & Cubs & 0.00 & 0.00 & 1.00 & \\
\hline & Yearling & 0.00 & 0.00 & & 1.00 \\
\hline & Twos & $0.75(0.28-0.97)$ & $0.25(0.03-0.76)$ & & \\
\hline \multirow[t]{4}{*}{ NSN } & Alone & $0.67(0.41-0.85)$ & $0.33(0.15-0.59)$ & & \\
\hline & Cubs & $0.17(0.02-0.63)$ & 0.00 & $0.83(0.15)$ & \\
\hline & Yearling & 0.00 & 0.00 & & 1.00 \\
\hline & Twos & 1.00 & 0.00 & & \\
\hline
\end{tabular}

TABLE 3 Reproductive state transition rates $( \pm 95 \% \mathrm{Cl}$ ) estimated using multistate models on reproductive data from collared adult female brown bears ( $\geq 6$ years) in the McGillvary Mountains and North Stein-Nahatlatch populations in southwestern British Columbia, Canada
McGillvary Mountains and 0.55 (95\% Cl: 0.38-0.84) in the North Stein-Nahatlatch (Table 3; Figure 3a).

\section{6 | Stable age distribution}

The difference in survival probabilities resulted in differences in the stable age distribution of each population (Figure 3b). The McGillvary Mountains had a higher proportion of yearling and subadult bears, whereas the North Stein-Nahatlatch had proportionately more adults and older bears (Figure $3 \mathrm{~b}$ ).

\section{7 | Population growth}

Mean estimates of projected population growth indicated that, given the estimated stable reproductive state and demographic rates, the McGillvary Mountains population should have grown with $\lambda=1.09$ (95\% Cl: 1.04-1.13) while the North Stein-Nahatlatch population should have declined with $\lambda=0.84$ (95\% Cl: 0.72-0.95) throughout 
(a)

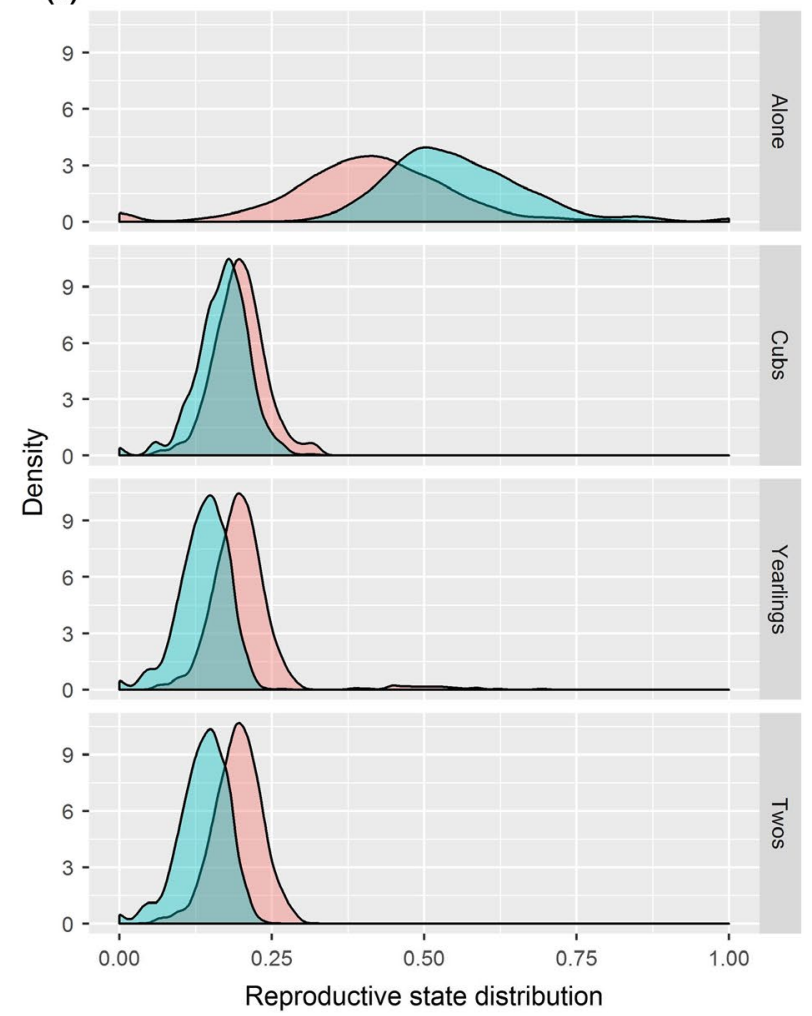

\section{(b)}

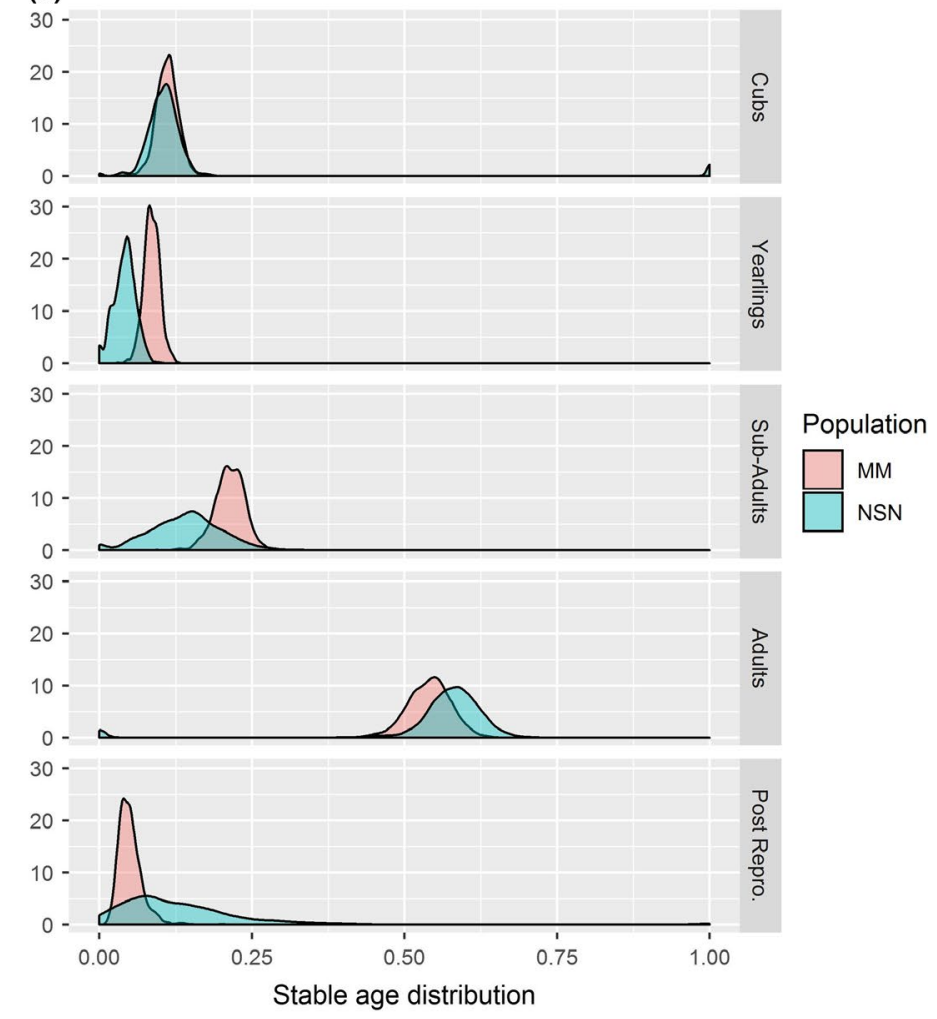

FIGURE 3 Density plots of (a) the stable reproductive state distribution estimated using in multi-state transition models on reproductive data from collared adult female brown bears ( $\geq 6$ years). (b) Bootstrapped estimates of the stable age distribution estimated from vital rates for grizzly bears in the McGillvary Mountains and North Stein-Nahatlatch populations in southwestern British Columbia, Canada

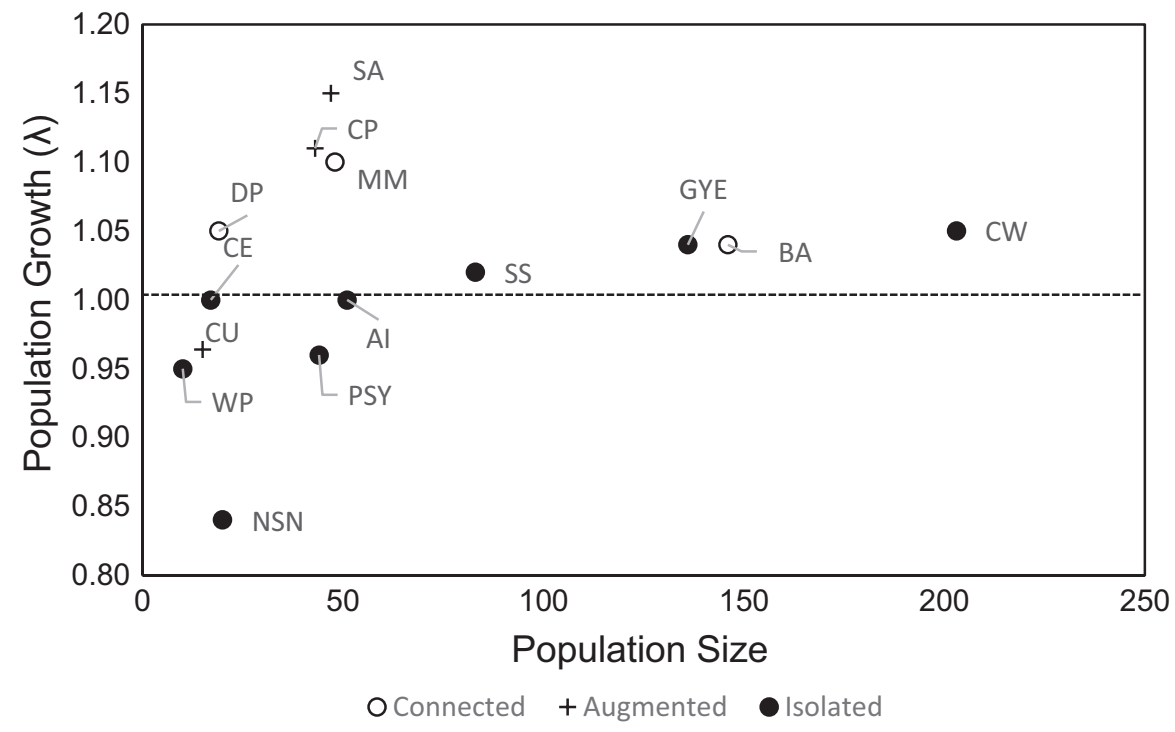

FIGURE 4 The relationship between brown bear population growth rate $(\lambda)$ and population size from this research and other unhunted populations including isolated populations ( $\bullet$ ), population with some connectivity to neighboring populations (O), and augmented populations (+). Populations are identified by letters: Al: Apennines, Italy (Gervasi et al., 2017); SA: Southern Alps, Europe (Tosi et al., 2015); BA: Banff, Canada (Garshelis et al., 2005); CU: Cabinet Mountains, USA (Kasworm et al., 2014; Kendall et al., 2016; Proctor et al., 2012; Wakkinen \& Kasworm, 2004); CE: Cantabrian East, Spain (Clevenger et al., 1987; Palomero et al., 2007; Pérez et al., 2014); CW: Cantabrian West, Spain (Clevenger et al., 1987; Palomero et al., 2007; Pérez et al., 2014); CP: Central Pyrenees, Spain-France (Chapron et al., 2009); DP: Deosai, Pakistan (Nawaz et al., 2008); MM: McGillvary Mountains, Canada; NSN: North Stein-Nahatlatch (This research, McLellan et al., 2019); PSY: Purcell-South Yaak (Proctor et al., 2012); WP: West Pyrenees, Spain-France (Chapron et al., 2009); GYE: Yellowstone, USA (Schwartz et al., 2006; van Manen et al., 2015) 
the study. The mean estimated generation time was 13.2 years $(95 \%$ $\mathrm{Cl}$ : 12.6-13.8) in the McGillvary Mountains and 11.7 years $(95 \% \mathrm{Cl}$ : 9.2-14.6) in the North Stein-Nahatlatch. In contrast, the net reproductive rate $\left(R_{0}\right)$ was over seventeen times higher in the McGillvary Mountains (3.03; 95\% Cl: 1.66-4.65), than in North Stein-Nahatlatch (0.17; $95 \% \mathrm{Cl}$ : 0.02-0.53) population.

\section{8 | Population growth estimates in small populations of brown bears}

Comparing population growth rates with those of other brown bear populations with available data showed that the projected increase in the McGillvary Mountains population was similar to other connected populations following reductions in human-caused mortality (Figure 4). In contrast, the projected decline in the North SteinNahatlatch population was very low but mirrored observed declines in other small and isolated brown bear populations.

\section{4 | DISCUSSION}

We used data from telemetered individuals in two adjacent but distinct brown bear populations in British Columbia, Canada, to measure the demographic components of population change following the elimination of human-caused mortality from legal hunting. Although both populations were in ecologically similar environments, one had triple the density and some genetic and demographic connectivity to neighboring bear populations, while the other was small ( $<25$ individuals) and genetically isolated. Despite similar management efforts, the larger, connected population we studied had higher independent female and cub survival rates than the small, isolated population resulting in widely divergent population trends.

\subsection{Small population inferences}

An interesting caveat of studying small populations with very few adult females is that vital rate estimates, and subsequent inferences, were unavoidably drawn from small sample sizes. Extreme outcomes (high and low) are common with small samples, and therefore, researchers have little confidence with small samples obtained from large populations. However, because the number of individuals we monitored approached the size of the entire population, we are confident that our population-specific estimates and projections are accurate for the period of study, but less confident that the results necessarily reflect systemic factors in the observed trends. Chance events can play a major role in the dynamics of small populations (Engen \& Sæther, 1998). If, by chance, a different group of females with the same genetic makeup had been living in the study area, we would likely have generated different estimates. Although we were sampling from an infinite potential population, our sample size was severely restricted to the few animals that were actually there.

\section{2 | Population growth estimates in small populations of brown bears}

Comparing data from the two populations we studied with other small, unhunted brown bear populations suggested some relationships among population size, connectivity, and population growth for the species. Although a statistically rigorous comparison was not possible due to the limited availability of vital rate estimates and their variances, small, isolated bear populations below approximately 50 individuals usually continued to decline even with efforts to reduce mortality unless they were augmented (Figure 4). This agrees with observations from other studies of small populations of carnivores. Small populations ( $n=31$ with data) of African wild dogs (Lycaon pictus) monitored over 15 years showed that $50 \%$ of populations with $\sim 50$ or fewer individuals declined to extirpation, while $75 \%$ of populations with 100 individuals increased over the same period (Woodroffe \& Sillero-Zubiri, 2020). The more cryptic Asiatic cheetah (Acinonyx jubatus venaticus) has also experienced population declines and likely extirpations of small isolates (Farhadinia et al., 2017).

\section{3 | Survival estimates in small populations of brown bears}

Survival rates in the larger, and connected McGillvary Mountains population, were typical of unhunted brown bear populations below carrying capacity. Under such conditions, adult female survival is usually $\geq 0.95$, subadult female survival ranges between 0.81 and 0.96 , yearling survival between 0.70 and 0.93 , and cub survival between 0.69 and 0.88 (e.g., Garshelis et al., 2005; Mace et al., 2012; McLellan, 2015; Schwartz et al., 2006; Wakkinen \& Kasworm, 2004). Adult female survival in the small and isolated North Stein-Nahatlatch population was much lower (0.81). Other small and isolated brown bear populations also report lower adult female survival rates (range between 0.91 and 0.93) (Chapron et al., 2009; Kasworm et al., 2007; Tosoni et al., 2017). In these populations, despite considerable conservation efforts, female survival was similar or even lower than in several heavily hunted brown bear populations (McLellan, 2015; Miller et al., 1997). High adult female mortality is further illustrated by the high natural mortality rate of 0.12 mortalities/bear-year of monitoring in the North Stein-Nahatlatch population; much higher than recorded in large populations where it ranged from $<0.005$ mortalities/bear-year monitoring in the Yellowstone Ecosystem (Schwartz et al., 2006) to 0.018 mortalities/bear-year monitoring in the Canadian Flathead (McLellan, 2015). The low adult female survival in the Stein-Nahatlatch population is likely hindering population recovery as population viability in long-lived, slow reproducing species is often heavily affected by adult female survival (de Silva \& Leimgruber, 2019; Heppell et al., 2000). 
Cub survival in the North Stein-Nahatlatch population was among the lowest documented for the species. Only a few highdensity, unhunted Alaskan populations in remote areas where they were thought to be at carrying capacity had similarly low cub survival (Keay et al., 2018; Sellers et al., 1999). We were unable to determine the specific causes of cub mortality because only their mothers were monitored directly. However, in addition to stochasticity, three different mechanisms may explain the low cub survival we observed in the North Stein-Nahatlatch population. First, low cub survival could indicate that the North SteinNahatlatch population is at a low-density carrying capacity and, at least in some years, limited by food. Second, concurrent long-term genetic monitoring of our study populations (McLellan et al., 2019) including an associated pedigree analysis identified multiple instances of parent-offspring and full sibling mating in the North Stein-Nahatlatch population (unpublished data). Studies measuring the effect of parent-offspring or full sibling mating found a $33 \%$ and $77 \%$ reduction in juvenile survival of various mammal species in zoos (Ralls et al., 1988) and wild ungulate populations (Walling et al., 2011), respectively. Third, infanticide by adult males may also have contributed to low cub survival (McLellan, 1994). Sexually selected infanticide has been documented in brown bears in Sweden (Swenson et al., 2001), and it may be exacerbated when the adult sex ratio favors males (Chapron et al., 2009; McLellan, 2005). In small populations with few adult females and long interbirth intervals, there will often be years when all adult females are with dependent offspring, and none are reproductively available (e.g., Gonzalez et al., 2016) likely resulting in an increased chance of infanticide and creating a component Allee effect on juvenile survival as the population decreases.

\subsection{Reproductive rates in small populations of brown bears}

Reproductive rates were similar in both of our study populations but generally lower than in other brown bear populations below carrying capacity (Mace et al., 2012; McLellan, 2015; Zedrosser et al., 2011). The reproductive state distributions of the two populations we studied suggest that adult females in the North SteinNahatlatch population may be without dependent offspring more frequently than in other brown bear populations (e.g., Garshelis et al., 2005; Schwartz et al., 2003; Støen et al., 2006), including the McGillvary Mountains. Long interbirth intervals and late age of primiparity contributed to an increased number of adult females without dependent offspring (offspring $\leq 2$ years) and the associated reduction in reproductive rates. Although the sample sizes used to estimate reproductive parameters in these populations are insufficient to support any definitive conclusions, the observed ages of primiparity in the North Stein-Nahatlatch were older than the 5-7 years of age at which females in most other populations reproduce (Mace et al., 2012; McLellan, 2015; Schwartz et al., 2006; but see Garshelis et al., 2005).

\section{5 | Small population dynamics}

The increased vulnerability of small populations to decline has been widely discussed, concluding that small populations of sexually reproducing diploids are subject to loss of genetic diversity and some form of Allee effect (Berec et al., 2007; Caughley, 1994; Frankham et al., 2019). Further, the effects of demographic stochasticity on population growth and the probability of extinction are increased in small populations. The random fluctuations in birth and death events have very little effect on population growth in large populations; however, in small populations, simultaneous "bad luck" among few individuals can cause the population to decline to zero (Engen \& Sæther, 1998). Fortunately, inbreeding and loss of genetic diversity are potentially reversible by restoring gene flow via augmentation or natural immigration (Åkesson et al., 2016; Poirier et al., 2019; Quinn et al., 2019; van de Kerk et al., 2019; Yumnam et al., 2014). An example is the genetic restoration of the Florida panthers (Puma concolor coryi) from population augmentation (Johnson et al., 2010) that increased survival of first generation admixed panthers in all age classes (van de Kerk et al., 2019). Natural immigration also appears to be contributing to the recent increase in the Western Cantabrian brown bear population (Pérez et al., 2014). Re-establishing connectivity with the growing McGillvary Mountains population by conserving unoccupied suitable habitat to geographically connect populations should be a primary focus of conservation management aimed at restoring the North Stein-Nahatlatch population.

Notwithstanding the prevalence of theory on small population dynamics, there are very few published examples of vital rates from wild populations with fewer than 30 individuals. Our research shows that the survival rates for both juveniles and adults in a small and isolated brown bear population were at the extreme range for what has been observed for the species in larger populations and significantly different from those observed in the neighboring but connected population. Our findings support the theory that as populations decline, we can expect wide variations in vital rates that diverge from those common for the species, potentially exacerbating the rate of decline (Lande, 1998). Also, that small, isolated populations of large carnivores may not respond as well to recovery actions that were successful for larger, or more connected populations of the same species (Fanshawe et al., 1991; Ferreras et al., 2001; Groom et al., 2014; Tosoni et al., 2017). For many carnivores, this means that solely focusing on reducing adult mortality is likely to be insufficient to promote recovery and should not be the only conservation strategy.

By understanding the demographic components of population change, and how they may differ in small populations compared to larger ones, we not only increase our understanding of the relationships between population size and the potential for recovery but also are better able to convincingly prescribe targeted populationspecific recovery initiatives.

\section{ACKNOWLEDGMENTS}

The Habitat Conservation Trust Foundation, the British Columbia Ministry of Forests, Lands, and Natural Resource Operations, and 
the Ministry of Environment provided funding. M. McLellan is thankful for a Victoria University of Wellington Ph.D. scholarship. We thank S. Rochetta and C. Doyon, for their contributions to fieldwork, C. Wilson and D. Mair for excellent piloting, and to M. Ritchie for proofreading this manuscript. M. Efford, P. Lester, and J. Belant provided many helpful comments on a previous version. We would like to thank four anonymous reviewers; their contributions greatly improved this manuscript. Much of this research was conducted in the traditional territory of the St'át'imc people.

\section{CONFLICT OF INTEREST}

None declared.

\section{AUTHOR CONTRIBUTION}

Michelle McLellan: Conceptualization (equal); Data curation (equal); Formal analysis (lead); Funding acquisition (supporting); Investigation (equal); Methodology (equal); Project administration (supporting); Resources (supporting); Writing-original draft (lead); Writingreview \& editing (lead). Bruce McLellan: Conceptualization (equal); Data curation (equal); Funding acquisition (lead); Investigation (equal); Methodology (equal); Project administration (equal); Resources (equal); Writing-review \& editing (equal). Rahel Sollmann: Supervision (supporting); Writing-review \& editing (equal). Heiko Wittmer: Funding acquisition (supporting); Methodology (supporting); Supervision (lead); Writing-review \& editing (equal).

\section{DATA AVAILABILITY STATEMENT}

Data are available at https://datadryad.org/stash/share/vuGxVQHVBxBsg1bLnV4593oycNImHHdS-FCsuDVbt4

\section{ORCID}

Michelle L. McLellan iD https://orcid.org/0000-0003-0034-2038

\section{REFERENCES}

Åkesson, M., Liberg, O., Sand, H., Wabakken, P., Bensch, S., \& Flagstad, Ø. (2016). Genetic rescue in a severely inbred wolf population. Molecular Ecology, 25, 4745-4756. https://doi.org/10.1111/mec.13797

Apps, C., Paetkau, D., Rochetta, S., McLellan, B., Hamilton, A., \& Bateman, B. (2014). Grizzly bear population abundance, distribution \& connectivity across British Columbia's southern Coast Ranges. Report vol 2.0. Victoria, BC.

Benazzo, A., Trucchi, E., Cahill, J. A., Delser, P. M., Mona, S., Fumagalli, M., Bunnefeld, L., Cornetti, L., Ghirotto, S., Girardi, M., Ometto, L., Panziera, A., Rota-Stabelli, O., Zanetti, E., Karamanlidis, A., Groff, C., Paule, L., Gentile, L., Vilà, C., ... Bertorelle, G. (2017). Survival and divergence in a small group: The extraordinary genomic history of the endangered Apennine brown bear stragglers. Proceedings of the National Academy of Sciences of the United States of America, 114, E9589-E9597. https://doi.org/10.1073/pnas.1707279114

Berec, L., Angulo, E., \& Courchamp, F. (2007). Multiple Allee effects and population management. Trends in Ecology \& Evolution, 22, 185-191. https://doi.org/10.1016/j.tree.2006.12.002

Brook, B. W., Sodhi, N. S., \& Bradshaw, C. J. A. (2008). Synergies among extinction drivers under global change. Trends in Ecology \& Evolution, 23, 453-460. https://doi.org/10.1016/j.tree.2008.03.011

Burnham, K. P., \& Anderson, D. R. (2004). Multimodel inference: Understanding $\mathrm{AIC}$ and $\mathrm{BIC}$ in model selection. Sociological Methods
\& Research, 33, 261-304. https://doi.org/10.1177/0049124104 268644

Caswell, H. (2001). Matrix population models: Construction, analysis, and interpretation (2nd ed.). Sinauer Associates.

Caughley, G. (1994). Directions in conservation biology. Journal of Animal Ecology, 63, 215-244. https://doi.org/10.17011/conference/eccb2 $018 / 107830$

Chapron, G., Quenette, P.-Y., Legendre, S., \& Clobert, J. (2003). Which future for the French Pyrenean brown bear (Ursus arctos) population? An approach using stage-structured deterministic and stochastic models. Comptes Rendus Biologies, 326, S174-S182. https://doi. org/10.1016/s1631-0691(03)00055-6

Chapron, G., Wielgus, R., Quenette, P. Y., \& Camarra, J. J. (2009). Diagnosing mechanisms of decline and planning for recovery of an endangered brown bear (Ursus arctos) population. PLoS One, 4, e7568. https://doi.org/10.1371/journal.pone.0007568

Clevenger, A. P., Purroy, F. J., Buruaga, M. S. D., Purdoy, F., \& Burguaga, M. S. D. (1987). Status of the brown bear in the Cantabrian Mountains, Spain. Bears: Their Biology and Management, 7, 1-8.

de Silva, S., \& Leimgruber, P. (2019). Demographic tipping points as early indicators of vulnerability for slow-breeding megafaunal populations. Frontiers in Ecology and Evolution, 7, 1-13. https://doi.org/10.3389/ fevo.2019.00171

Engen, S., \& Sæther, B.-E. (1998). Stochastic population models: Some concepts, definitions and results. Oikos, 83, 345-352.

Fanshawe, J. H., Frame, L. H., \& Ginsberg, J. R. (1991). The wild dog Africa's vanishing carnivore. Oryx, 25, 137-146.

Farhadinia, M. S., Hunter, L. T. B., Jourabchian, A., Hosseini-Zavarei, F., Akbari, H., Ziaie, H., Schaller, G. B., \& Jowkar, H. (2017). The critically endangered Asiatic cheetah Acinonyx jubatus venaticus in Iran: A review of recent distribution, and conservation status. Biodiversity and Conservation, 26, 1027-1046. https://doi.org/10.1007/s1053 1-017-1298-8

Ferreras, P., Gaona, P., Palomares, F., \& Delibes, M. (2001). Restore habitat or reduce mortality? Implications from a population viability analysis of the Iberian lynx. Animal Conservation, 4, 265-274. https://doi. org/10.1017/S1367943001001317

Frankham, R., Ballou, J. D., Ralls, K., Eldridge, M. D. B., Dudash, M. R., Fenster, C. B., Lacy, R. C., \& Sunnucks, P. (2019). A practical guide for genetic management of fragmented animal and plant populations (1st ed.). Oxford University Press. https://doi.org/10.1093/oso/97801 98783411.001.0001

Fujiwara, M., \& Diaz-Lopez, J. (2017). Constructing stage-structured matrix population models from life tables: Comparison of methods. PeerJ, 5, e3971. https://doi.org/10.7717/peerj.3971

Garshelis, D. L., Gibeau, M. L., \& Herrero, S. (2005). Grizzly bear demographics in and around Banff National Park and Kananaskis Country, Alberta. Journal of Wildlife Management, 69, 277-297. https://doi. org/10.2193/0022-541x(2005)069<0277:gbdiaa>2.0.co;2

Garshelis, D. L., Noyce, K. V., \& Coy, P. L. (1998). Calculating the average age of first reproduction free of the biases prevalent in bear studies. Ursus, 10, 437-447.

Gervasi, V., Boitani, L., Paetkau, D., Posillico, M., Randi, E., \& Ciucci, P. (2017). Estimating survival in the Apennine brown bear accounting for uncertainty in age classification. Population Ecology, 59, 119-130. https://doi.org/10.1007/s10144-017-0587-0

Gonzalez, E. G., Blanco, J. C., Ballesteros, F., Alcaraz, L., Palomero, G., \& Doadrio, I. (2016). Genetic and demographic recovery of an isolated population of brown bear Ursus arctos L., 1758. PeerJ, 4, e1928. https://doi.org/10.7717/peerj.1928

Gough, K. F., \& Kerley, G. I. H. (2006). Demography and population dynamics in the elephants Loxodonta africana of Addo Elephant National Park, South Africa: Is there evidence of density dependent regulation? Oryx, 40, 434-441. https://doi.org/10.1017/S0030 605306001189 
Groom, R. J., Funston, P. J., \& Mandisodza, R. (2014). Surveys of lions Panthera leo in protected areas in Zimbabwe yield disturbing results: What is driving the population collapse? Oryx, 48, 385-393. https:// doi.org/10.1017/S0030605312001457

Haroldson, M. A., van Manen, F. T., Ebinger, M. R., Higgs, M. D., Bjornlie, D. D., Gunther, K. A., Frey, K. L., Cain, S. L., \& Aber, B. C. (2014). Trends in causes and distribution, and effects of whitebark pine decline on grizzly bear mortality in the Greater Yellowstone Ecosystem. Intermountain Journal of Sciences, 20, 59715.

Henschel, P., Coad, L., Burton, C., Chataigner, B., Dunn, A., MacDonald, D., Saidu, Y., \& Hunter, L. T. B. (2014). The lion in West Africa is critically endangered. PLoS One, 9, e83500. https://doi.org/10.1371/ journal.pone.0083500

Heppell, S. S., Caswell, H., \& Crowder, L. B. (2000). Life histories and elasticity patterns: Perturbation analysis for species with minimal demographic data. Ecology, 81, 654-665.https://doi. org/10.1890/0012-9658(2000)081[0654:LHAEPP]2.0.CO;2

Hood, G. (2011). PopTools v.3.2.5.

Johnson, W. E., Onorato, D. P., Roelke, M. E., Land, E. D., Cunningham, M., Belden, R. C., McBride, R., Jansen, D., Lotz, M., Shindle, D., Howard, J., Wildt, D. E., Penfold, L. M., Hostetler, J. A., Oli, M. K., \& O'Brien, S. J. (2010). Genetic restoration of the Florida panther. Science, 329, 1641-1645. https://doi.org/10.1126/science.1192891

Kasworm, W. F., Proctor, M. F., Servheen, C., \& Paetkau, D. (2007). Success of grizzly bear population augmentation in Northwest Montana. Journal of Wildlife Management, 71, 1261-1266. https://doi. org/10.2193/2006-266

Kasworm, W. F., Radandt, T. G., Teisberg, J. E., \& Servheen, C. (2014). Cabinet-Yaak grizzly bear recovery area 2013 research and monitoring progress report. Missoula, MT.

Keay, J. A., Robbins, C. T., \& Farley, S. D. (2018). Characteristics of a naturally regulated grizzly bear population. Journal of Wildlife Management, 82, 789-801. https://doi.org/10.1002/jwmg.21425

Kendall, K. C., Macleod, A. C., Boyd, K. L., Boulanger, J., Royle, J. A., Kasworm, W. F., Paetkau, D., Proctor, M. F., Annis, K., \& Graves, T. A. (2016). Density, distribution, and genetic structure of grizzly bears in the Cabinet-Yaak Ecosystem. Journal of Wildlife Management, 80, 314-331. https://doi.org/10.1002/jwmg.1019

Kendall, K. C., Stetz, J. B., Boulanger, J., MacLeod, A. C., Paetkau, D., \& White, G. C. (2009). Demography and genetic structure of a recovering brown bear population. Journal of Wildlife Management, 73, 3-17. https://doi.org/10.2193/2008-330

Kenney, J., Allendorf, F. W., McDougal, C., \& Smith, J. L. D. (2014). How much gene flow is needed to avoid inbreeding depression in wild tiger populations? Proceedings of the Royal Society B-Biological Sciences, 281, 1-8. https://doi.org/10.1098/rspb.2013.3337

Kindberg, J., Swenson, J. E., Ericsson, G., Bellemain, E., Miquel, C., \& Taberlet, P. (2011). Estimating population size and trends of the Swedish brown bear Ursus arctos population. Wildlife Biology, 17, 114-123. https://doi.org/10.2981/10-100

Laake, J. J., \& Rexstad, E. (2008). RMark-An alternative approach to building linear models. Appendix C. In E. Cooch, \& G. C. White (Eds.), Program MARK: A gentle introduction (pp. C1-C111). Nordic Board for Wildlife Research.

Lande, R. (1998). Anthropogenic, ecological and genetic factors in extinction and conservation. Researches on Population Ecology, 40, 259269. https://doi.org/10.1007/BF02763457

Mace, R. D., Carney, D. W., Chilton-Radandt, T., Courville, S. A., Haroldson, M. A., Harris, R. B., Jonkel, J., McLellan, B. N., Madel, M., Manley, T. L., Schwartz, C. C., Servheen, C., Stenhouse, G., Waller, J. S., \& Wenum, E. (2012). Grizzly bear population vital rates and trend in the Northern Continental Divide Ecosystem, Montana. Journal of Wildlife Management, 76, 119-128. https://doi.org/10.1002/ jwmg.250
MacKenzie, W. (2012). Biogeoclimatic ecosystem classification program of non-forested ecosystems in British Columbia. Province of British Columbia.

Mattson, D. J., \& Merrill, T. (2002). Extirpations of grizzly bears in the contiguous United States, 1850-2000. Conservation Biology, 16, 1123-1136. https://doi.org/10.1046/j.1523-1739.2002.00414.x

McLellan, B. N. (1994). Density-dependent population regulation of brown bears. In International Conference on Bear Research and Management Monograph Series (pp. 15-24).

McLellan, B. N. (2005). Sexually selected infanticide in grizzly bears: The effects of hunting on cub survival. Ursus, 16, 141-156.https://doi. org/10.2192/1537-6176(2005)016[0141:ssiigb]2.0.co;2

McLellan, B. N. (2015). Some mechanisms underlying variation in vital rates of grizzly bears on a multiple use landscape. Journal of Wildlife Management, 79, 749-765. https://doi.org/10.1002/jwmg.896

McLellan, B. N., \& Hovey, F. W. (2001). Natal dispersal of grizzly bears. Canadian Journal of Zoology, 79, 838-844. https://doi.org/10.1139/ z01-051

McLellan, B. N., Proctor, M. F., Huber, D., \& Michel, S. (2017). Brown Bear Ursus arctos (amended version of 2017 assessment). The IUCN Red List of Threatened Species.

McLellan, M. L., \& McLellan, B. N. (2015). Effect of season and high ambient temperature on activity levels and patterns of grizzly bears (Ursus arctos). PLoS One, 10, 1-14. https://doi.org/10.1371/journ al.pone.0117734

McLellan, M. L., McLellan, B. N., Sollmann, R., Lamb, C. T., Apps, C. D., \& Wittmer, H. U. (2019). Divergent population trends following the cessation of legal grizzly bear hunting in southwestern British Columbia, Canada. Biological Conservation, 233, 247-254. https://doi. org/10.1016/j.biocon.2019.02.021

Miller, S. D., White, G. C., Sellers, R. A., Reynolds, H. V., Schoen, J. W., Titus, K., Barnes, V. G., Smith, R. B., Nelson, R. R., Ballard, W. B., \& Schwartz, C. C. (1997). Brown and black bear density estimation in Alaska using radiotelemetry and replicated mark-resight techniques. Wildlife Monographs, 133, 1-55.

Mosnier, A., Doniol-Valcroze, T., Gosselin, J. F., Lesage, V., Measures, L. N., \& Hammill, M. O. (2015). Insights into processes of population decline using an integrated population model: The case of the St. Lawrence Estuary beluga (Delphinapterus leucas). Ecological Modelling, 314, 15-31. https://doi.org/10.1016/j.ecolmodel.2015.07.006

Nawaz, M. A., Swenson, J. E., \& Zakaria, V. (2008). Pragmatic management increases a flagship species, the Himalayan brown bears, in Pakistan's Deosai National Park. Biological Conservation, 141, 22302241. https://doi.org/10.1016/j.biocon.2008.06.012

Palomero, G., Ballesteros, F., Nores, C., Blanco, J. C., Herrero, J., \& García-Serrano, A. (2007). Trends in number and distribution of brown bear females with cubs-of-the-year in the Cantabrian Mountains, Spain. Ursus, 18, 145-157.https://doi. org/10.2192/1537-6176(2007)18[145:tinado]2.0.co;2

Pérez, T., Naves, J., Vázquez, J. F., Fernández-Gil, A., Seijas, J., Albornoz, J., Revilla, E., Delibes, M., \& Domínguez, A. (2014). Estimating the population size of the endangered Cantabrian brown bear through genetic sampling. Wildlife Biology, 20, 300-309. https://doi.org/10.2981/wlb.00069

Poirier, M. A., Coltman, D. W., Pelletier, F., Jorgenson, J., \& FestaBianchet, M. (2019). Genetic decline, restoration and rescue of an isolated ungulate population. Evolutionary Applications, 12, 13181328. https://doi.org/10.1111/eva.12706

Pollock, K. H., Winterstein, S. R., Bunck, C. M., \& Curtis, P. D. (1989). Survival analysis in telemetry studies: The staggered entry design. Journal of Wildlife Management, 53, 7-15.

Proctor, M. F., McLellan, B. N., Strobeck, C., \& Barclay, R. M. (2004). Gender-specific dispersal distances of grizzly bears estimated by genetic analysis. Canadian Journal of Zoology, 82, 1108-1118. https:// doi.org/10.1139/Z04-077 
Proctor, M. F., Paetkau, D., McLellan, B. N., Stenhouse, G. B., Kendall, K. C., MacE, R. D., Kasworm, W. F., Servheen, C., Lausen, C. L., Gibeau, M. L., Wakkinen, W. L., Haroldson, M. A., Mowat, G., Apps, C. D., Ciarniello, L. M., Barclay, R. M. R., Boyce, M. S., Schwartz, C. C., \& Strobeck, C. (2012). Population fragmentation and interecosystem movements of grizzly bears in Western Canada and the Northern United States. Wildlife Monographs, 180, 1-46. https://doi. org/10.1002/wmon.6

Quinn, C. B., Alden, P. B., \& Sacks, B. N. (2019). Noninvasive sampling reveals short-term genetic rescue in an insular red fox population. Journal of Heredity, 110, 559-576. https://doi.org/10.1093/jhered/esz024

R Core Team (2019). R: A language and environment for statistical computing.

Raglus, T. I., De Groef, B., Rochfort, S., Rawlin, G., \& McCowan, C. (2019). Bone marrow fat analysis as a diagnostic tool to document ante-mortem starvation. The Veterinary Journal, 243, 1-7. https://doi. org/10.1016/j.tvjl.2018.11.001

Ralls, K., Ballou, J. D., \& Templeton, A. (1988). Estimates of lethal equivalents and the cost of inbreeding in mammals. Conservation Biology, 2, 185-193.

Regehr, E. V., Hostetter, N. J., Wilson, R. R., Rode, K. D., Martin, M. S., \& Converse, S. J. (2018). Integrated population modeling provides the first empirical estimates of vital rates and abundance for polar bears in the Chukchi Sea. Scientific Reports, 8, 1-12. https://doi. org/10.1038/s41598-018-34824-7

Ripple, W. J., Estes, J. A., Beschta, R. L., Wilmers, C. C., Ritchie, E. G., Hebblewhite, M., Berger, J., Elmhagen, B., Letnic, M., Nelson, M. P., Schmitz, O. J., Smith, D. W., Wallach, A. D., \& Wirsing, A. J. (2014). Status and ecological effects of the world's largest carnivores. Science, 343, 1241484. https://doi.org/10.1126/science.1241484

Schwartz, C. C., Haroldson, M. A., White, G. C., Harris, R. B., Cherry, S., Keating, K. A., Moody, D., \& Servheen, C. (2006). Temporal, spatial, and environmental influences on the demographics of grizzly bears in the Greater Yellowstone Ecosystem. Wildlife Monographs, 161, 1-68.

Schwartz, C. C., Keating, K. A., Reynolds, H. V., Barnes, V. G., Sellers, R. A., Swenson, J. E., Miller, S. D., McLellan, B. N., Keay, J., McCann, R., Gibeau, M., Wakkinen, W. F., Mace, R. D., Kasworm, W., Smith, R., \& Herrero, S. (2003). Reproductive maturation and senescence in the female brown bear. Ursus, 14, 109-119. https://doi. org $/ 10.2307 / 3873012$

Schwartz, C. C., \& White, G. C. (2008). Estimating reproductive rates for female bears: Proportions versus transition probabilities. Ursus, 19, 1-12. https://doi.org/10.2192/07gr003r.1

Sellers, R. A., Miller, S. D., Smith, T. S., Potts, R., \& (1999). Population dynamics of a naturally regulated brown bear population on the coast of Katmai National Park and Preserve. Final Report. Anchorage. http:// www.adfg.alaska.gov/static/home/library/pdfs/wildlife/research_ pdfs/population_dynamics_brown_bear_katmai_national_park.pdf

Spedicato, G. A., Kang, T. S., Yalamanchi, S. B., Yadav, D., \& Cordon, I. (2014). The markovchain package: A package for easily handling discrete Markov chains in R.

Støen, O. G., Zedrosser, A., Wegge, P., \& Swenson, J. E. (2006). Socially induced delayed primiparity in brown bears Ursus arctos. Behavioral Ecology and Sociobiology, 61, 1-8. https://doi.org/10.1007/s00265-006-0231-z

Stubben, C., \& Milligan, B. (2007). Estimating and analyzing demographic models using the popbio package in R. Journal of Statistical Software, 22, 1-23.

Swenson, J. E., Sandegren, F., Brunberg, S., \& Segerström, P. (2001). Factors associated with loss of brown bear cubs in Sweden. Ursus, 12, 69-80. https://doi.org/10.2307/3873232

Swenson, J. E., Wabakken, P., Sandegren, F., Bjärvall, A., Franzén, R., \& Söderberg, A. (1995). The near extinction and recovery of brown bears in Scandinavia in relation to the bear management policies of Norway and Sweden. Wildlife Biology, 1, 11-25. https://doi. org/10.2981/wlb.1995.005
Tosi, G., Chirichella, R., Zibordi, F., Mustoni, A., Giovannini, R., Groff, C., Zanin, M., \& Apollonio, M. (2015). Brown bear reintroduction in the Southern Alps: To what extent are expectations being met? Journal for Nature Conservation, 26, 9-19. https://doi.org/10.1016/j. jnc.2015.03.007

Tosoni, E., Boitani, L., Gentile, L., Gervasi, V., Latini, R., \& Ciucci, P. (2017). Assessment of key reproductive traits in the Apennine brown bear population. Ursus, 28, 105-116. https://doi.org/10.2192/ URSU-D-16-00025.1

van de Kerk, M., Onorato, D. P., Hostetler, J. A., Bolker, B. M., \& Oli, M. K. (2019). Dynamics, persistence, and genetic management of the endangered Florida Panther population. Wildlife Monographs, 203, 335. https://doi.org/10.1002/wmon.1041

van Manen, F. T., Haroldson, M. A., Bjornlie, D. D., Ebinger, M. R., Costello, C. M., \& White, G. C. (2015). Density dependence, whitebark pine, and vital rates of grizzly bears. Journal of Wildlife Management, 80 , 1-14. https://doi.org/10.1002/jwmg.1005

van Oort, H., McLellan, B. N., \& Serrouya, R. (2011). Fragmentation, dispersal and metapopulation function in remnant populations of endangered mountain caribou. Animal Conservation, 14, 215-224. https://doi.org/10.1111/j.1469-1795.2010.00423.x

Wakkinen, W. L., \& Kasworm, W. F. (2004). Demographics and population trends of grizzly bears in the Cabinet-Yaak and Selkirk Ecosystems of British Columbia, Idaho, Montana, and Washington. Ursus, 15, 65-75. https://doi.org/10.2192/1537-6176(2004)015<0065:daptog>2.0.co;2

Walling, C. A., Nussey, D. H., Morris, A., Clutton-Brock, T. H., Kruuk, L. E. B., \& Pemberton, J. M. (2011). Inbreeding depression in red deer calves. BMC Evolutionary Biology, 11, 318. https://doi. org/10.1186/1471-2148-11-318

White, G. C. (2008). Closed population estimation models and their extensions in Program MARK. Environmental and Ecological Statistics, 15, 89-99. https://doi.org/10.1007/s10651-007-0030-3

Wittmer, H. U., McLellan, B. N., Seip, D. R., Young, J. A., Kinley, T. A., Watts, G. S., \& Hamilton, D. (2005). Population dynamics of the endangered mountain ecotype of woodland caribou (Rangifer tarandus caribou) in British Columbia, Canada. Canadian Journal of Zoology, 83, 407-418. https://doi.org/10.1139/z05-034

Woodroffe, R., \& Sillero-Zubiri, C. (2020). Lycaon pictus, African Wild Dog (amended version of 2012 assessment). The IUCN Red List of Threatened Species 2020: e.T12436A166502262. https://dx.doi. org/10.2305/IUCN.UK.2020-1.RLTS.T12436A166502262.en

Yumnam, B., Jhala, Y. V., Qureshi, Q., Maldonado, J. E., Gopal, R., Saini, S., Srinivas, Y., \& Fleischer, R. C. (2014). Prioritizing tiger conservation through landscape genetics and habitat linkages. PLoS One, 9, e111207. https://doi.org/10.1371/journal.pone.0111207

Zedrosser, A., Dahle, B., Swenson, J. E., \& Gerstl, N. (2001). Status and management oh the brown bear in Europe. Ursus, 12, 9-20. https:// doi.org/10.2307/3873224

Zedrosser, A., Steyaert, S. M. J. G., Gossow, H., \& Swenson, J. E. (2011). Brown bear conservation and the ghost of persecution past. Biological Conservation, 144, 2163-2170. https://doi.org/10.1016/j. biocon.2011.05.005

Zipkin, E. F., \& Saunders, S. P. (2018). Synthesizing multiple data types for biological conservation using integrated population models. Biological Conservation, 217, 240-250. https://doi.org/10.1016/j. biocon.2017.10.017

How to cite this article: McLellan ML, McLellan BN, Sollmann $\mathrm{R}$, Wittmer HU. Vital rates of two small populations of brown bears in Canada and range-wide relationship between population size and trend. Ecol Evol. 2021;00:1-13. https:// doi.org/10.1002/ece3.7301 